\title{
Optimization of process parameters for kitchen waste composting by response surface methodology
}

\author{
M. K. Iqbal • A. Nadeem • F. Sherazi • \\ R. A. Khan
}

Received: 24 July 2013/Revised: 4 February 2014/Accepted: 10 March 2014/Published online: 4 June 2014

(C) Islamic Azad University (IAU) 2014

\begin{abstract}
The optimization of process parameters for decomposition of kitchen waste into mature, stable compost was investigated using response surface methodology (RSM). RSM and central composite designs were applied to evaluate and optimize the key factors namely fly ash, bulking agent for moisture optimization and temperature, inoculum size and lime concentration for $\mathrm{C} / \mathrm{N}$ optimization, which affect the stability of compost. Moisture and $\mathrm{C} / \mathrm{N}$ ratio were selected as response variables. The experimental data of response variables were fitted into quadratic polynomial model using the multiple regression analysis and found it was statistically significant quadratic model. Box-Behnken design under RSM was used to optimize their interaction between bulking agent (40\%) and fly ash $(15 \%)$ has significant effect on moisture optimization and temperature $\left(35^{\circ} \mathrm{C}\right)$, lime $(3 \%)$, and inoculum size $(10 \%)$ were the best for $\mathrm{C} / \mathrm{N}$ ratio optimization and compost maturity. These optimized conditions were used and recorded the $50 \%$ moisture reduction, and $8.43 \mathrm{C} / \mathrm{N}$ was achieved; indicates the stable and mature compost in minimum time. A significant correlation was also found between $\mathrm{C} / \mathrm{N}$ ratio, humic acid, fulvic acid and degree of polymerization during compost formation. It was fleetingly concluded that optimization of compost parameters promote the decomposition rate and humification process.
\end{abstract}

Keywords Compost - Decomposition - Humification . Inoculum $\cdot$ Moisture $\cdot \mathrm{C} / \mathrm{N}$

M. K. Iqbal $(\varangle)$ · F. Sherazi · R. A. Khan

PCSIR Labs, Lahore, Pakistan

e-mail: drkhichi75@gmail.com

A. Nadeem

Government College University Faisalabad, Faisalabad, Pakistan

\section{Introduction}

The amount of kitchen waste generated in developing countries is the major organic municipal solid waste (MSW) (50-64\%), due to rapid development. These wastes can cause hygienic hazards, odor and ground water pollution by leaching of pollutants, if not properly treated (Guo et al. 2012).

Pakistan as an agricultural country needs high quantity of organic fertilizers due to inflation in fertilizers prices and to improve crop yield and maintain nutrient status of soil (Iqbal et al. 2010b). Fresh and immature waste is unsuitable for direct application to land, may inhibit seed germination, reduce plant growth or cause phytotoxicity to plants due to incomplete biodegradation of organic matter (Gao et al. 2010).

Composting is an effective and economical method for the treatment of waste prior to land application. The environmental conditions and substrate characteristics influence the composting process. Like these factors moisture impacts also on the physico-chemical properties [temperature, free air space (FAS), particle size, $\mathrm{pH}, \mathrm{C} / \mathrm{N}$ ] of waste material to decompose during composting process (Kulcu and Yaldiz 2004). Several researchers also reported that optimum moisture content $(55-60 \%), \mathrm{C} / \mathrm{N}$ ratio (25-30) and $\mathrm{pH}$ are the important factors for stabilization and maturation of compost (Sundberg et al. 2013; Kumar et al. 2010). Bulking agents are the fibrous with carbonaceous material, provide FAS and regulate water contents of waste to be composted because they modify the properties of waste during composting, due to high moisture, low $\mathrm{C} / \mathrm{N}$ ratio and high density of waste. Rice husk was used as bulking agent for the adjustment of $\mathrm{C} / \mathrm{N}$ ratio, moisture contents, to promote the growth of degrading microbes and fasten composting process. Similarly role of additives; lime 
and fly ash consider rising of $\mathrm{pH}$, temperature and $\mathrm{CO}_{2}$ evolution without any negative effect on the microbial community for stabilization and maturation of compost (Chang et al. 2006; Wong and Fang 2000). During composting, the fly ash and lime neutralized the acid formation in fermentation of carbohydrates and fats, which lowers the $\mathrm{pH}$ of the composting mass leading to the retardation of decomposition efficiency. The fly ash has been previously investigated as soil amendments for agricultural use, due to its capacity and $\mathrm{Ca}, \mathrm{Mg}$ oxides, to improve the physical and chemical properties of soil and plants (Wong et al. 2009). Moreover, the combined use of fly ash and lime in calculated and small quantity may result in an efficient removal of pathogens and enhance the decomposition rate for mature and stable compost.

However, to acquire significant and highly stabilized compost, the optimal operating conditions should be optimized, which plays a vital role in developing process and enhancing their performance. It is not an easy chore because various factors are involved during composting. Several authors have conducted single-factor optimization to evaluate the optimum process conditions. This method is unreliable and may lead to misinterpretation of results and it does not depict the interactive effects among the variables and guarantee the determination of optimal conditions (Mannan et al. 2007). Recently, statistics-based experimental design has been reported in the literature, which is time saving and reduce the error in determining the interactive consequence of process parameters.

Response surface methodology (RSM) is used for the optimization of studies in several research and development (R\&D) works. It proves a quite and reliable statistical method for minimum experiments. Usharani and Muthukumar (2013) used the Box-Behnken design experiment for the removal of methylparathion by applying the different operating variables (temperature, $\mathrm{pH}$, agitation and reaction time) and noted the biodegradation of methylparathion, removal of chemical oxygen demand (COD), total carbon and specific growth rate as response. The role of RSM was also evaluated during the biohydrogen production from Rhodobacter sphaeroides O.U.001 by optimizing the growth parameters (Hay et al. 2012). Jadhav et al. (2013) applied the RSM for the decolorization of dyes from water and found the encouraging results during their study. It has also been used to determine the optimal values for processing parameters, i.e., $\mathrm{pH}$, temperature, feeding rates and aeration (Bazaraa and Hassan 1996).

Consequently, the main objective of this study was to investigate the impact of moisture and additives; lime and fly ash on stability, maturity and nutrients status of compost using the Box-Behnken design under RSM. Present research work was conducted in PCSIR laboratories complex Lahore, Pakistan and was completed in September 2012.
Table 1 Chemical properties of composted wastes

\begin{tabular}{lcll}
\hline Parameters & Kitchen waste & Rice husk & Mixture \\
\hline Moisture (\%) & 69.84 & 5 & 54 \\
$\quad$ Ash (\%) & 5.2 & 17.01 & 7.23 \\
Volatile matter (\%) & 21.6 & 65.28 & 31.92 \\
Fixed carbon (\%) & 3.36 & 12.71 & 6.85 \\
Carbon (\%) & 36.84 & 40.75 & 29.32 \\
Nitrogen (\%) & 1.3 & 0.45 & 0.85 \\
Hydrogen (\%) & 5.8 & 5.44 & 4.09 \\
Sulphur (\%) & 0.2 & 0.26 & 0.82 \\
Oxygen (\%) & 50.66 & 36.09 & 57.89 \\
Organic matter (\%) & 94.8 & 83 & 92.77 \\
C/N & 28.34 & 90.55 & 34.49 \\
\hline
\end{tabular}

All results are average of three values

\section{Materials and methods}

Feed stocks

All the wastes were collected from Lahore University Pakistan hostels, includes eggshells, breads, cooked rice, fruit and vegetables, and meat and wood ash were hauled to PCSIR laboratories complex Lahore. Rice husk was selected as bulking agent and purchased from local market, passed through mesh machine ranged from 0.5 to $1 \mathrm{~mm}$. The chemical composition (moisture, ash, total carbon, nitrogen, sulphur, volatile matter, fixed carbon, $\mathrm{C} / \mathrm{N}$ ratio) of feed stocks was analyzed before mixing for composting process (Table 1).

\section{Optimization by RSM}

The optimization of compost parameters were accomplished using statistical design of experiments in two stages. The first stage involved in the optimization of moisture parameter and second stage involved the significant variables (temperature, lime and inoculum size) for $\mathrm{C} / \mathrm{N}$ ratio optimization. Prior to concentrate the process/process variables during research work required a complete understanding of practical model. Box-Behnken design consists of a group of controlled experimental factors and measured responses, according to one or more selected criteria. BoxBehnken design has three levels low $(-1)$, medium $(0)$ and high $(+1)$, and it is more efficient, easier to manage and interpret for comparison with others. In the present study, in first stage, bulking agent and fly ash variables were selected to determine the optimum quantity of each variable for optimized moisture concentration (50\%) and in second step lime, temperature and inoculum size variables were chosen for $\mathrm{C} / \mathrm{N}$ ratio optimization, i.e., production of mature, stable compost in minimum time using the RSM. The preset 
Table 2 Quantities of raw material for moisture optimization

\begin{tabular}{llll}
\hline S. no. & $\begin{array}{l}\text { Bulking } \\
\text { agent }(\%)\end{array}$ & $\begin{array}{l}\text { Fly } \\
\text { ash }(\%)\end{array}$ & $\begin{array}{l}\text { Kitchen } \\
\text { waste }(\%)\end{array}$ \\
\hline 1 & 10 & 15 & 75 \\
2 & 10 & 5 & 85 \\
3 & 25 & 10 & 65 \\
4 & 25 & 10 & 65 \\
5 & 40 & 15 & 45 \\
6 & 25 & 17 & 58 \\
7 & 25 & 10 & 65 \\
8 & 25 & 10 & 65 \\
9 & 3.78 & 10 & 86.22 \\
10 & 28 & 2.9 & 69.1 \\
11 & 40 & 5 & 55 \\
12 & 25 & 10 & 65 \\
13 & 46 & 10 & 44 \\
\hline
\end{tabular}

ranges of independent variables for moisture optimization, i.e., bulking agent (10-40\%) and fly ash (5-15\%), whereas for $\mathrm{C} / \mathrm{N}$ ratio optimization, i.e., temperature $\left(25-35{ }^{\circ} \mathrm{C}\right)$, lime (1-4\%) and inoculums size (5-10\%) for second stage experiment were investigated in this study (Tables 2,3 ). In the present study, two-by-three factorial design was employed to fit the second order polynomial model, which indicates the required experiments: 13 for first stage and 15 for second stage, respectively. All the experiments were carried out in triplicates according to design matrix, which was based on number of variables. The independent variable for moisture (fly ash and bulking agent) and for $\mathrm{C} / \mathrm{N}$ (lime, temperature and inoculum size) and mathematical relationship of response $Y_{1}$ and $Y_{2}$ of these variables were approximated by quadratic polynomial equations for moisture and $\mathrm{C} / \mathrm{N}$ ratio optimization, respectively as

$Y_{1}=\beta_{0}+\beta_{1} X_{1}+\beta_{2} X_{2}+\beta_{11} X_{1}^{2}+\beta_{22} X_{2}^{2}++\beta_{12} X_{1} X_{2}$

where $Y_{1}$ is the predicted response, $\beta_{0}$ is the constant, $\beta_{1}$, $\beta_{2}$, are the linear co-efficient, $\beta_{11}, \beta_{22}$ are the quadratic coefficient and $\beta_{12}$, are the cross-product coefficients.

$$
\begin{aligned}
Y_{2}= & \beta_{0}+\beta_{1} X_{1}+\beta_{2} X_{2}+\beta_{3} X_{3}+\beta_{11} X_{1}^{2}+\beta_{22} X_{2}^{2}+\beta_{33} x_{3}^{2} \\
& +\beta_{12} X_{1} X_{2}+\beta_{13} X_{1} X_{3}+\beta_{23} X_{2} X_{3}
\end{aligned}
$$

$Y_{2}$ is the predicted response, $\beta_{0}$ is the constant, $\beta_{1}, \beta_{2}, \beta_{3}$ are the linear co-efficient, $\beta_{11}, \beta_{22}, \beta_{33}$ are the quadratic coefficient and $\beta_{12}, \beta_{13}, \beta_{23}$ are the cross-product coefficients. The optimum values of the selected variables were obtained by solving the regression equation.

This design was used to evaluate the interaction and quadratic effects of moisture and other compost parameters
Table 3 Central composite design matrix along with experimental and predicted values of moisture optimization

\begin{tabular}{lclll}
\hline Std & Bulking agent & Fly ash & Experimental & Predicted \\
\hline 1 & 1 & 1 & 65.8 & 66.09 \\
2 & 1 & 1 & 69.34 & 68.97 \\
3 & 0 & 1 & 64.78 & 64.78 \\
4 & 0 & 1 & 64.78 & 64.78 \\
5 & 1 & 1 & 50.01 & 49.94 \\
6 & -1 & 1 & 60.32 & 60.07 \\
7 & 0 & 1 & 64.78 & 64.78 \\
8 & 0 & 1 & 64.78 & 64.78 \\
9 & -1 & 1 & 67.9 & 67.87 \\
10 & -1 & 1 & 64.66 & 65.34 \\
11 & 1 & 1 & 55.23 & 54.51 \\
12 & 0 & 1 & 64.78 & 64.78 \\
13 & -1 & 1 & 45.76 & 46.23 \\
\hline
\end{tabular}

for mature and stabilized compost preparation. The statistical software design (version: 16) was used for experimental design, data analysis and graph plotting.

Experimental setup

The kitchen waste was mixed thoroughly after manual cutting and assured that mixture was homogeneous. The kitchen waste, bulking agent and fly ash were mixed as per design format in plastic containers for periods of 7 days under controlled laboratory conditions $\left(T: 25^{\circ} \mathrm{C} ; \mathrm{H}: 50 \%\right)$ and calculated the potential of moisture reduction as prescribed by Iqbal et al. (2010a). The quantities of raw materials processed during moisture optimization were presented in Table 2. In first stage, all the trials 1-13 for moisture optimization were exercised for a period of 7 days and observed the trial no. (5) of Table 3 composition best and optimized the moisture $(50 \%)$. The data of trials 2,5 and 13 were only presented because only these three trials, minimum, middle and maximum moisture optimization were noted. The optimized combination (trial no.: 5) was composted by adding the quantities of lime, inoculum (cow dung) and temperature as experimental RSM design in $4 \mathrm{~kg}$ capacity tray, placed in calibrated oven $\left( \pm 1{ }^{\circ} \mathrm{C}\right)$ at laboratory scale. The quantities of raw material to be composted were comprised of bulking agent $(1.6 \mathrm{~kg})$, fly ash $(0.6 \mathrm{~kg})$ and kitchen waste $(1.8 \mathrm{~kg})$. The trials 1-15 (Table 4) were composted as per design conditions and only trials 1,5 and 15 chemical changes during the composting process were reported because $\mathrm{C} / \mathrm{N}$ ratio and other chemical changes of other trials did not show the maturity and stability earlier.

All of experimental replicates, moisture (50\%), were maintained by sprinkling the water, and aeration was given 
Table 4 Box-Behnken design matrix along with experimental and predicted values of $\mathrm{C} / \mathrm{N}$ optimization

\begin{tabular}{lrrrrr}
\hline Std & Temperature & Lime & $\begin{array}{l}\text { Inoculum } \\
\text { size }\end{array}$ & Experimental & Predicted \\
\hline 1 & -1 & -1 & 0 & 11.65 & 10.85 \\
2 & 1 & -1 & 0 & 23.97 & 24.11 \\
3 & -1 & 1 & 0 & 31.32 & 31.18 \\
4 & 1 & 1 & 0 & 29.08 & 29.89 \\
5 & -1 & 0 & -1 & 17.86 & 17.74 \\
6 & 1 & 0 & -1 & 27.67 & 26.60 \\
7 & -1 & 0 & 1 & 21.43 & 22.50 \\
8 & 1 & 0 & 1 & 25.49 & 25.61 \\
9 & 0 & -1 & -1 & 14.78 & 15.70 \\
10 & 0 & 1 & -1 & 29.67 & 29.93 \\
11 & 0 & -1 & 1 & 19.02 & 18.76 \\
12 & 0 & 1 & 1 & 31.56 & 30.64 \\
13 & 0 & 0 & 0 & 8.43 & 8.43 \\
14 & 0 & 0 & 0 & 8.43 & 8.43 \\
15 & 0 & 0 & 0 & 8.43 & 8.43 \\
\hline
\end{tabular}

to each replicate after 7 days of interval. Three replicates of each trial were given individual attention to diminish the external fracas, distressing the composting process.

Periodically, about $100 \mathrm{~g}$ of samples was removed from all trials at days $0,7,14,21,28,35,42,49,63$ and 77 for physical and chemical analyses of compost. Samples were dried at $75{ }^{\circ} \mathrm{C}$ and passed through 2-mm sieve according to Iqbal et al. (2010b).

\section{Analytical methods}

Measurement of total $\mathrm{N}, \mathrm{C}, \mathrm{S}$ and $\mathrm{H}$ in kitchen waste, bulking agent (rice husk) and composts was taken on dried sample by catalytic tube combustion using Vario Macro elementar CHNOS analyzer (S.N: 11046079). The C/N ratio was calculated as the quotient of total carbon over total nitrogen.

The $\mathrm{pH}$ (Jenco-6173) of compost material was determined by adding $10 \mathrm{~g}$ of compost in $100 \mathrm{ml}$ of double distilled water for $24 \mathrm{~h}$ under laboratory conditions $\left(25^{\circ} \mathrm{C}\right)$, whereas the ash and organic matter were also determined according to the guidelines of ASTM (Bailey and Baldini 2007). The $\mathrm{Na}$ and $\mathrm{K}$ were determined using flame photometer (Jenway PFP). The ammonium-N and phosphate were determined using the APHA (2005).

The compost sample humic acid was determined by shaking $1.0 \mathrm{~g}$ in $30 \mathrm{ml} 0.1 \mathrm{M} \mathrm{NaOH}$ for a period of $20 \mathrm{~h}$. It was centrifuged at $10,000 \mathrm{rpm}$ for $10 \mathrm{~min}$ to get clear supernatant contain humic acid (HA) and fulvic acid (FA) fractions, and its part $(15 \mathrm{ml})$ were also acidified with strong acid $\mathrm{H}_{2} \mathrm{SO}_{4}$. After this acidified suspension for standing of $12 \mathrm{~h}$ was centrifuged, separated and determined the HA and FA contents as per guidelines of Aparna et al. (2008).

The degree of polymerization (DP) was determined by dividing of HA over FA. The DP was calculated according to Senesi (1989).

$\mathrm{DP}=\mathrm{HA} / \mathrm{FA}$

Statistical analysis

Each physico-chemical characteristics of waste and compost was analyzed three times, and their results were reported as an average along with standard deviation. Statistical analysis was also carried using SPSS 17 for Pearson's correlation between FA, HA, DP and C/N of compost parameters.

\section{Results and discussion}

First stage for moisture optimization

The chemical composition of kitchen waste and bulking agent impacts on physical and chemical properties of mature and stable compost. One of the important constituents of compost is carbon more abundant in bulking agent than kitchen waste. It was exploited by micro-organism to construct an energy platform for their survival during composting. The $\mathrm{C} / \mathrm{N}$ ratio of bulking agent, kitchen waste and mixture was 90.55, 28.34 and 34.49, respectively (Table 1). Composting is a biological process; its efficacy is dependent on various factors among these factors moisture has critical attention during the decomposition of organic matter because it impinge on the microbial activity, leads to rise in temperature and curtail the time of compost maturity (Kumar et al. 2010).

Kitchen waste in the present study contains $69.84 \%$ moisture, which was optimized using the bulking agent (rice husk) and fly ash in different ratios as per RSM. Both rice husk and fly ash showed the escalating trend in moisture absorption from kitchen waste as the ratio of each rise. Bulking agents have the property to modify the physical (bulk density, FAS) and chemical $(\mathrm{C} / \mathrm{N})$ properties of compost. They not only absorb the moisture contents but also impact on the $\mathrm{C} / \mathrm{N}$ ratio of the compost (Iqbal et al. 2010a). Fly ash is a product of combustion, contains macro nutrients $(\mathrm{CaO}, \mathrm{Na}, \mathrm{K})$, perk up the physical and chemical characteristics of compost along with reduction in moisture from the composting matrix. The similar observations were found in the present study, i.e., reduction in moisture by the addition of bulking agent and fly ash. The different ratios of bulking agent and fly ash had shown variation in their moisture absorption with time, but combination as per 

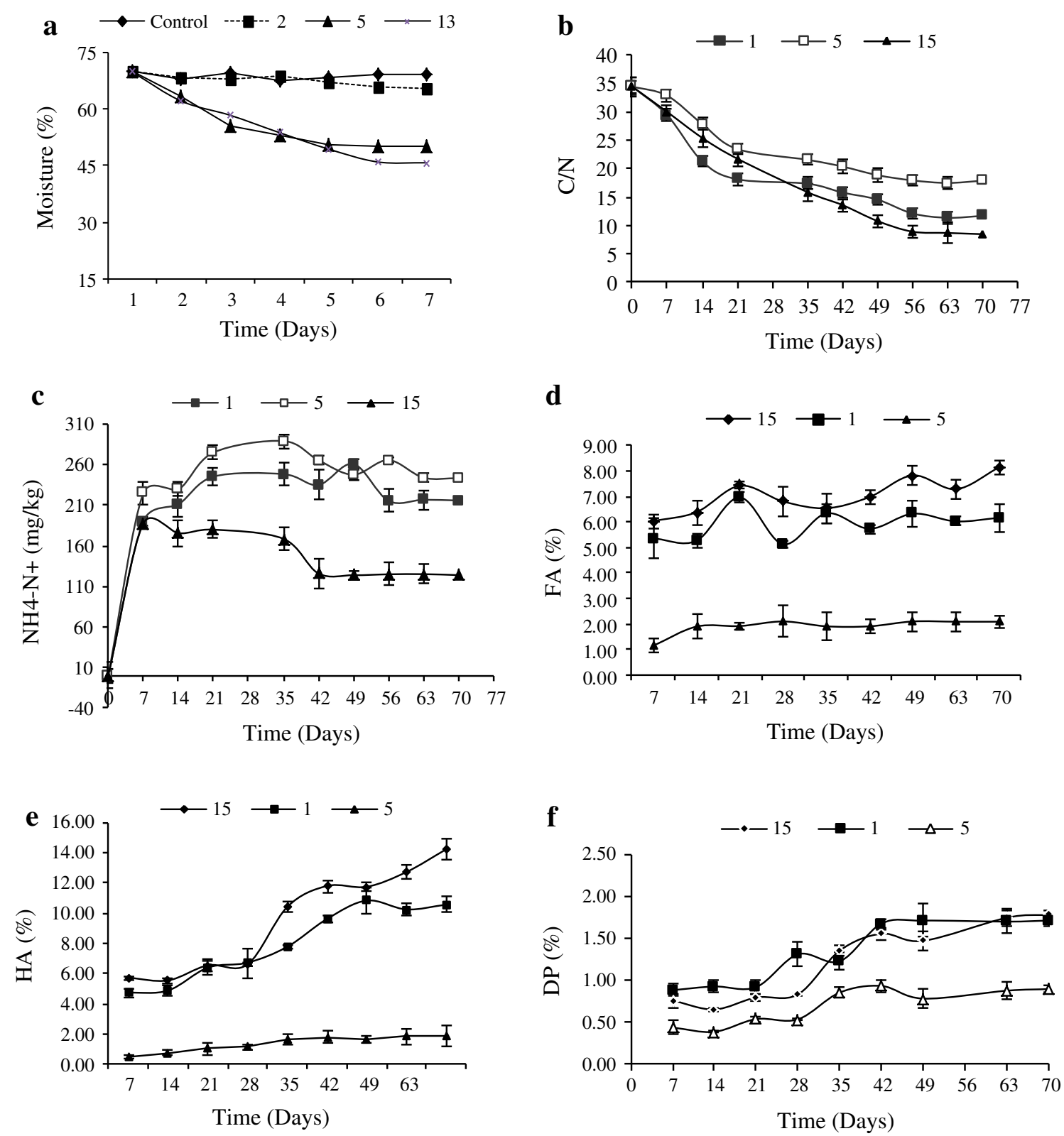

Fig. 1 Variation of chemical properties of compost with time a moisture optimization, $\mathbf{b} \mathrm{C} / \mathrm{N}$ optimization, $\mathbf{c}$ ammonium/nitrate ratio, $\mathbf{d}$ FA, e HA and $\mathbf{f}$ DP

CCD (kitchen waste: 45 ; bulking agent: 40 and fly ash: 15) illustrates suitable moisture absorption for composting process up to $50 \%$. It was also noted that there was a significant difference of trial (5) than other combinations/ trials. The trial (13) absorbed maximum moisture in respect of all trials, whereas trial (5) absorbed 23.44 and $27.86 \%$ more moisture than trial (2) and control, respectively. Trail (13) moisture reduction reduces the biological activity of the composting process. The optimum time for moisture reduction up to $50 \%$ was 5 days for trial 5 and after this did not exhibit the variation in their results (Fig. 1a). Hence, it limits the ability to absorb the leachate during kitchen waste composting. Iqbal et al. (2010a) used saw dust (40\%) as bulking agent during the optimization of physical properties of MSW compost and found the attractive results and the present study results are also inline with Guo et al. (2012). The trials 2, 5 and 13 are illustrated in Fig. 1a, while other trials shown the results on the same pattern as per design format ratio of bulking agent and fly ash.

\section{Second stage for $\mathrm{C} / \mathrm{N}$ optimization}

The changes in $\mathrm{C} / \mathrm{N}$ ratio give an indication of nitrogen availability for biological degradation of organic waste, and decline with time has been widely reported as an 
indicator of compost stability and maturity because microorganism used this carbon as energy source and nitrogen for building cell structure (Iqbal et al. 2010b). The variation in $\mathrm{C} / \mathrm{N}$ with time is shown in Fig. $1 \mathrm{~b}, \mathrm{C} / \mathrm{N}$ ratio decreased with time in all the trials, due to strong mineralization process took place in early stage of composting which was evident by sizeable diminution and augmentation in the total organic carbon and nitrogen levels, respectively, in all trials; as a result the $\mathrm{C} / \mathrm{N}$ ratio decreased consistently as the composting progressed, with about a 14.67, 4.7 and $13 \%$ decrease within the first 7 days in the trials 1,5 and 15 , respectively. In the preliminary phase of composting the lessening of carbon due to bio-oxidation of carbon to $\mathrm{CO}_{2}$ cloud be attributed to the positive impact of lime and this increases the rate of biodegradation (Fang and Wong 1999), whereas the excessive concentration of lime inhibits the activity of micro-organism due high $\mathrm{pH}$ of the composting matrix, degree of humification and $\mathrm{C} / \mathrm{N}$ ratio decline was clogged in all other trials according to $\mathrm{pH}$ and lime concentration (data not shown). At the end of composting process, a decrease of about 66.22, 48.22 and $75.56 \%$ of the initial $\mathrm{C} / \mathrm{N}$ ratio (34.49\%) was seen for the 1,5 and 15 trials, respectively.

These findings in the present study concurred with the results reported by Guo et al. (2012) and it was also noted that there was no significant difference in trials 5 and 1 , whereas a great significant difference was present with trial 15. According to Golueke (1981), a C/N ratio below 20 is an indicator of acceptable maturity and ratio of 15 or less is preferable. This ratio represents the forms of organic carbon and nitrogen in the composting mixture that are more susceptible to microbial transformation and therefore, more conscientious for compost stability and maturity than total content of organic carbon and nitrogen part of the bulk organic matter (Said-Pullicino et al. 2007).

Ammonification in the start of the investigation was much more in all trials. The amount of water-soluble $\mathrm{NH}_{4}$ $\mathrm{N}(\mathrm{mg} / \mathrm{kg})$ increased continuously up to 21 and 14 days of composting in trials 1,5 and 15 , respectively, and later diminished substantially at the termination of the composting process (Fig. 1c). The metabolism of protein enhances the concentration of ammonia due to microbial activities and its reduction was due to volatilization of gaseous ammonia having the alkaline $\mathrm{pH}$ of compost. However, the major contribution of the removal of the $\mathrm{NH}_{4}-\mathrm{N}$ shows the nitrification (Iqbal et al. 2010b). The conversion of ammonia into nitrates by the action of nitrifying bacteria is the final sink of nitrogen during composting. The soluble nitrates increased throughout the composting process due to transformation of ammonia to nitrate by nitrifier (data not shown).

The humification process is the result of the degradation of lignin to aromatic units, which occurs mostly during the thermophilic phase and the subsequent biosynthesis from the condensation and polymerization of aromatic units and cellular debris. It is initiated during composting by microbes that entails polymerization of low molecular weight units. This process conform the maturity and stability of compost by the decomposition of non-humic into humic substances and the concentration of HA was more than FA in all trials of present study. These results are also in lined with those of Iqbal et al. (2010b).

The healthier and enhanced HA concentration was noted in trials 1 and 15 rather than 5 due to the optimum temperature and by the addition of optimized lime concentration in trials 1 and 15 , whereas other trials did not exhibit its behavior like these trials. In trial 5, the temperature was not raised due to excessive concentration of lime which inhibits the microbial activity due to rise of $\mathrm{pH}$, and hence, the HA production percentage was least and adjournment (Fig. 1e).

The HA concentrations were enhanced throughout the composting process in all trials. The contents of HA ranged from 5.72 to $14.22,4.72-10.55$ and $0.5-1.87$ in trials 15,1 and 5 , respectively. On the other hand, FA production increased at the start of the process, whereas it exhibited decline in the remaining period of the process in all trials but the maximum production was achieved by trial 15 (Fig. 1d). These findings coincide with the results reported by Guo et al. (2012) and it was also observed that there was no significant difference in trial 5 and 1 whereas a great significant difference was present of trial 15 with trial 5 and 1. According to Golueke (1981) a $\mathrm{C} / \mathrm{N}$ ratio below 20 is an indicator of acceptable maturity and ratio of 15 or less is preferable. This ratio represents the forms of organic carbon and nitrogen in the composting mixture that are more susceptible for microbial transformation and for compost stability and maturity (Said-Pullicino et al. 2007). Iqbal et al. (2010a) findings are coherent to the present findings.

The other humification parameters (DP, HI and HR) were also optimized during the controlled composting process. Only the DP data have been illustrated and found the increasing trend through the composting process in all trails, but increasing behavior was not similar in all the trails due to the decomposition rate and its $\mathrm{C} / \mathrm{N}$ ratio. The similar pattern like HI was observed in DP with increase of 57.31, 48.53 and $51.68 \%$ of trials 15,1 and 5, respectively, when compared with the initial concentration of DP. It was also noted that there was no significant difference between trials 15 and 1, but a great and significant difference was observed with trial 5. DP in trial 15 was $50 \%$ more than in trial 5 (Fig. 1f). The same observation was noted by Tejada et al. (2009) in their study.

Correlation between chemical parameters of compost

The decomposition of kitchen waste into compost is a biological process and chemical parameters of compost 
Table 5 Pearson's correlation of compost parameters

\begin{tabular}{lllll}
\hline & $\mathrm{CN}$ & $\mathrm{HA}$ & $\mathrm{FA}$ & $\mathrm{DP}$ \\
\hline $\mathrm{C} / \mathrm{N}$ & 1 & $-0.808^{* *}$ & $-0.643^{*}$ & $-0.806^{* *}$ \\
$\mathrm{HA}$ & & 1 & $0.746^{*}$ & $0.993^{* *}$ \\
$\mathrm{FA}$ & & & 1 & $0.707^{*}$ \\
$\mathrm{DP}$ & & & & 1 \\
\hline
\end{tabular}

** Correlation is significant at the 0.01 level (2-tailed)

* Correlation is significant at the 0.05 level (2-tailed)

i.e., $\mathrm{C} / \mathrm{N}, \mathrm{HA}, \mathrm{FA}$ and DP having strong correlation with each other. Pearson's correlation was studies and found the $\mathrm{C} / \mathrm{N}$ ratio has negative correlation with $\mathrm{HA}, \mathrm{FA}$ and $\mathrm{DP}$ because during the process $\mathrm{C} / \mathrm{N}$ ratio becomes lessen with the passage of time and production of HA, FA and DP enhanced. They are principally inversely correlated with each other in exhibiting the positive sign of composting process. The positive and strong correlation of HA was found with FA in initial stages of composting, which lessen due the enhancement in DP at the end of the compost process. It means DP showed the positive correlation with HA and negative correlation with FA at the end of the process (Table 5 ). The same observation has been found by Iqbal et al. (2010b) in their study during the composting of MSW.

\section{Optimization of moisture and $\mathrm{C} / \mathrm{N}$ ratio}

Box-Behnken design under RSM was used to evaluate the interactive impact of lime, temperature and inoculum size to get an optimum combination for the production of mature and stable compost from kitchen waste.
The design matrix of these variables (bulking agent, fly ash) for moisture optimization and (lime, temperature and inoculum size) for $\mathrm{C} / \mathrm{N}$ ratio was in coded units are presented in Tables 3 and 4 along with experimental and predicted values of each. The predicted values for moisture and $\mathrm{C} / \mathrm{N}$ were obtained using the quadratic model fitting techniques by software design. The multiple regression analysis methods were applied by developing the statistical model on the use of experimental results of moisture and $\mathrm{C} / \mathrm{N}$.

These can be given as

$$
\begin{aligned}
Y_{1}= & 64.9721+0.405078\left(X_{1}\right)+0.596558\left(X_{2}\right) \\
& +-0.0171833\left(X_{1} X_{1}\right)+-0.0414500\left(X_{2} X_{2}\right) \\
& +-0.00560000\left(X_{1} X_{2}\right) \\
Y_{2}= & 328.599+-18.6363\left(X_{1}\right)+4.42562\left(X_{2}\right) \\
& +-3.39725\left(X_{3}\right)+0.298600\left(X_{1} X_{1}\right)+2.02750\left(X_{2} X_{2}\right) \\
& +0.288700\left(X_{3} X_{3}\right)+-0.364000\left(X_{1} X_{2}\right) \\
& +-0.0575000\left(X_{1} X_{3}\right)+-0.0587500\left(X_{2} X_{3}\right) .
\end{aligned}
$$

The statistical model was analyzed by $F$ test and the analysis of variance (ANOVA) for the response surface quadratic model is presented in Table 6. The model $F$ test value of 567.60 and 105.19 implies that the model is highly significant in both moisture and $\mathrm{C} / \mathrm{N}$ ratio optimization, respectively. The probability values were

\begin{tabular}{|c|c|c|c|c|c|c|c|}
\hline & Source & $d f$ & Seq SS & Adj SS & Adj MS & $F$ & $P$ \\
\hline \multirow[t]{8}{*}{ Moisture } & Regression & 5 & 602.780 & 602.780 & 120.556 & 567.60 & 0.000 \\
\hline & Linear & 2 & 496.086 & 496.086 & 248.043 & 1167.83 & 0.000 \\
\hline & Square & 2 & 105.988 & 105.988 & 52.994 & 249.51 & 0.000 \\
\hline & Interaction & 1 & 0.706 & 0.706 & 0.706 & 3.32 & 0.111 \\
\hline & Residual error & 7 & 1.487 & 1.487 & 0.212 & & \\
\hline & Lack-of-fit & 3 & 1.487 & 1.487 & 0.496 & & \\
\hline & Pure error & 4 & 0.000 & 0.000 & 0.000 & & \\
\hline & Total & 12 & 604.266 & & & & \\
\hline \multirow[t]{8}{*}{$\mathrm{C} / \mathrm{N}$} & Regression & 9 & $1,037.98$ & $1,037.98$ & 115.331 & 105.19 & 0.000 \\
\hline & Linear & 3 & 419.50 & 419.50 & 139.835 & 127.55 & 0.000 \\
\hline & Square & 3 & 555.83 & 555.83 & 185.277 & 168.99 & 0.000 \\
\hline & Interaction & 3 & 62.64 & 62.64 & 20.882 & 19.05 & 0.004 \\
\hline & Residual error & 5 & 5.48 & 5.48 & 1.096 & & \\
\hline & Lack-of-fit & 3 & 5.48 & 5.48 & 1.827 & & \\
\hline & Pure error & 2 & 0.00 & 0.00 & 0.000 & & \\
\hline & Total & 14 & $1,043.46$ & & & & \\
\hline
\end{tabular}
very low, as shown in Table 7; lesser than 0.05 indicates that the results of moisture and $\mathrm{C} / \mathrm{N}$ ratio can be fitted well by a second order response surface plot. Such $P$ values $<0.05$ indicated that the model is highly significant. The same observation was found by Kumar

Table 6 Analysis of variance for moisture and $\mathrm{C} / \mathrm{N}$ optimization 
Table 7 Estimated regression coefficients for moisture and $\mathrm{C} / \mathrm{N}$ optimization

\begin{tabular}{|c|c|c|c|c|c|}
\hline & Term & Coeff & SE coeff & $T$ & $P$ \\
\hline \multirow[t]{7}{*}{ Moisture } & Constant & $64.7,800$ & 0.2061 & 313.306 & 0.000 \\
\hline & Bulking agent & -7.6513 & 0.1629 & -46.958 & 0.000 \\
\hline & Fly ash & -1.8622 & 0.1629 & -11.429 & 0.000 \\
\hline & Bulking agent*bulking agent & -3.8662 & 0.1747 & -22.127 & 0.000 \\
\hline & Fly ash*fly ash & -1.0363 & 0.1747 & -5.930 & 0.001 \\
\hline & Bulking agent*fly ash & -0.4200 & 0.2304 & -1.823 & 0.111 \\
\hline & & $R^{2}=99.75 \%$ & & $R^{2}(\operatorname{adj})=99.58 \%$ & \\
\hline \multirow[t]{11}{*}{$\mathrm{C} / \mathrm{N}$} & Constant & 8.4300 & 0.6045 & 13.945 & 0.000 \\
\hline & Temperature & 2.9938 & 0.3702 & 8.087 & 0.000 \\
\hline & Lime & 6.5263 & 0.3702 & 17.629 & 0.000 \\
\hline & Inoculum size & 0.9400 & 0.3702 & 2.539 & 0.052 \\
\hline & Temperature*temperature & 7.4650 & 0.5449 & 13.699 & 0.000 \\
\hline & Lime*lime & 8.1100 & 0.5449 & 14.883 & 0.000 \\
\hline & Inoculum size*inoculum size & 7.2175 & 0.5449 & 13.245 & 0.000 \\
\hline & Temperature*lime & -3.6400 & 0.5235 & -6.953 & 0.001 \\
\hline & Temperature*inoculum size & -1.4375 & 0.5235 & -2.746 & 0.041 \\
\hline & Lime*inoculum size & -0.5875 & 0.5235 & -1.122 & 0.313 \\
\hline & & $R^{2}=99.47 \%$ & & $R^{2}(\operatorname{adj})=98.53 \%$ & \\
\hline
\end{tabular}

et al. (2010); they composted the green and food waste by applying the RSM to obtain the optimal operating condition for mature compost. The lack-of-fit value is another evidence that all the model coefficients namely bulking agent, fly ash, bulking agent ${ }^{2}$, fly $\mathrm{ash}^{2}$, bulking agent and fly ash for moisture optimization, whereas for $\mathrm{C} / \mathrm{N}$ ratio model coefficients are temperature, lime, inoculum size, temperature ${ }^{2}$, lime $^{2}$, inoculum size ${ }^{2}$, lime and temperature, temperature and inoculum size, lime and inoculum size are all these significant coefficients. The goodness of model was checked by determination coefficient (regression coefficient) $R^{2}$ and by adjusted $R^{2}$ (multiple correlation coefficients $R$ ). The value of determination coefficient $R^{2}$ for moisture optimization $(99.75 \%)$ and $(99.47 \%)$ for $\mathrm{C} / \mathrm{N}$ ratio indicates that only 0.25 and $0.53 \%$ were not explained by the model, respectively.

The adjusted coefficient [Adj. $R^{2}=99.58 \%$ (moisture) and $98.53 \%(\mathrm{C} / \mathrm{N})]$ for both moisture and $\mathrm{C} / \mathrm{N}$ was also high, which depicted the significance and goodness of the experimental work and closer the values of adjusted $R^{2}$ to 1 , indicates the better correlation between experimental and predicted values (Wang and Lu 2005). The predicted $R^{2}$ for moisture was $98.25 \%$ is in reasonable agreement with the adjusted $R^{2}(99.58 \%)$ between the experimental and predicted value for moisture reduction optimization. The same type of observation was found in $\mathrm{C} / \mathrm{N}$ ratio case, i.e., the predicted and adjusted values were not significantly different. The adequate precision measures the signal to noise ratio. A ratio $>4$ is desirable (Mannan et al. 2007). In the present study, the precision ratio for moisture and $\mathrm{C} / \mathrm{N}$ ratio is $>4$, which indicates that the model has an acceptable signs.

The fitted response surface plot was generated by statistically significant above the model by design expert program to understand the interaction between parameters during the optimization of moisture and $\mathrm{C} / \mathrm{N}$. The moisture optimization is the main stream requirement for the decomposition of waste, better for stable $\mathrm{C} / \mathrm{N}$ ratio of the compost, which indicates that other parameters like HA, FA, CEC, DP, HI are stable, and hence, compost will be mature and stable, used for the application of plant growth.

The contour plots were plotted in each parameter optimization, and two variables of each model were plotted at any one time on $X$ and $Y$ axes with the yield in $Z$-axis. The other one residual variable set at their middle point values automatically by the software to make each plot.

The shape of contour plots (elliptical, circular) presented that whether the interaction between factors is significant or not. The circular contour plot indicates the interaction between factors is also significant. The impact of bulking agent and fly ash for moisture optimization is shown in Fig. 2a, described that with the rise of quantity of bulking agent and fly ash, the moisture of kitchen waste decreases. In addition, the intense color of contour plot is directly proportional to concentration of moisture; means as the contour plot color light, the moisture also revealed the decline in its concentration. In addition the impact of lime, 


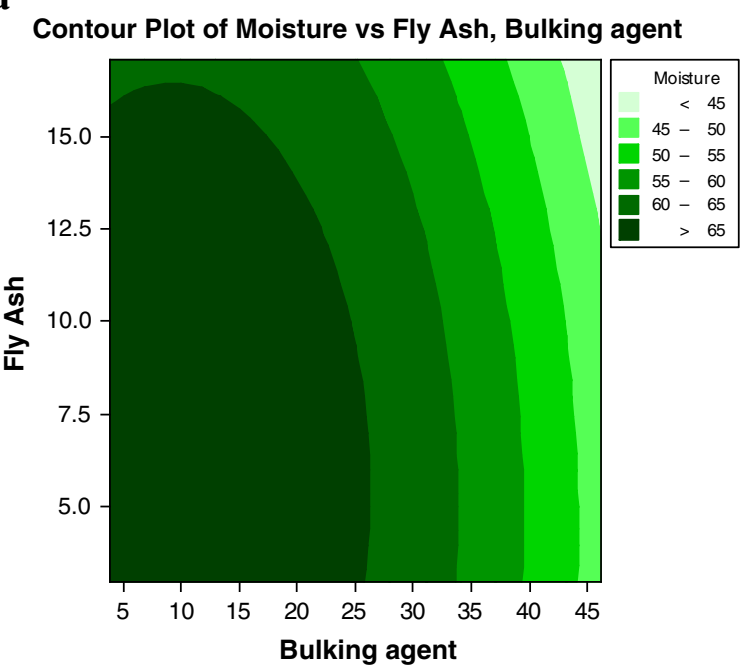

b
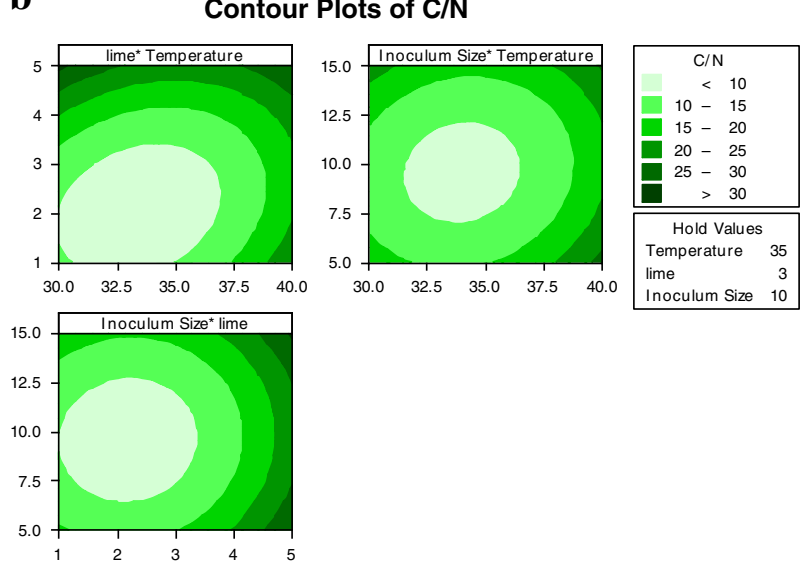

Fig. 2 Three-dimensional surface plots. a Moisture optimization and b $\mathrm{C} / \mathrm{N}$ optimization

temperature and inoculum size for $\mathrm{C} / \mathrm{N}$ ratio optimization exhibit the same behavior as by bulking agent and fly ash in moisture optimization Fig. 2b. The excessive use of lime and temperature variation hinders the microbial activity, resulted raise the maturity and stability time for compost.

By solving the Eqs. (1) and (2) using the software, the optimum values for moisture optimization were as bulking agent $40 \%$ and fly ash $15 \%$, whereas for $\mathrm{C} / \mathrm{N}$ ratio the temperature $35{ }^{\circ} \mathrm{C}$, inoculum $10 \%$ and lime $3 \%$ are the optimized parameters for the decomposition of kitchen waste into stable and mature compost. The predicted values for moisture and $\mathrm{C} / \mathrm{N}$ ratio were 49.94 and 8.33, respectively.

\section{Validation of model}

Different trials were conducted during the optimization of compost parameters for the formation of mature and stable compost from kitchen waste. Moisture plays an important role during the decomposition of waste because microorganism need FAS $>30 \%$, which was optimized by the addition of bulking agent and fly ash proportions, help to propagate the humus (HA and FA) formation ultimately decreases in the $\mathrm{C} / \mathrm{N}$ ratio with the passage of time under the optimum conditions of temperature $\left(35^{\circ} \mathrm{C}\right)$, inoculum $(10 \%)$ and lime $(3 \%)$. These results were observed better than conventional process for the formation of compost.

\section{Conclusion}

Co-composting of kitchen waste with bulking agent, fly ash, inoculum and lime was carried out successfully under optimized conditions by RSM, represent an effective and mature compost $(\mathrm{C} / \mathrm{N}$ : 8.3). The factorial experiment ANOVA results delivered statistically significant quadratic model have demonstrated the high accuracy for the process optimization within the defined ranged. Such optimization methods cannot lead misinterpretation of results as the conventional process are time consuming and monotonous.

Acknowledgments The present research was conducted and supported by Pakistan Council of Scientific and Industrial Research (PCSIR) Lahore with collaboration of university of Lahore; Raiwind road, Lahore, Pakistan.

\section{References}

Aparna C, Saritha P, Himabindu V, Anjaneyulu Y (2008) Techniques for the evaluation of maturity for composts of industrially contaminated lake sediments. Waste Manag 28:1773-1784

APHA (2005) Standard methods for the examination of water and waste water, 21st edn. APHA, Washington, pp 34-40

Bailey SJ, Baldini NC (2007) Annual book of ASTM standards. ASTM International, USA, 11.04, pp 775-776

Bazaraa WA, Hassan EE (1996) Response surface optimization for the continuous glucose isomerization process. J Ind Microbiol 17:100-103

Chang JI, Tsai JJ, Wu KH (2006) Thermophilic composting of food waste. Bioresour Technol 97(1):116-122

Fang M, Wong JWC (1999) Effects of lime amendment on availability of heavy metals and maturation in sewage sludge composting. Environ Pollut 106(1):83-89

Gao M, Liang F, Yu A, Yang L (2010) Evaluation of stability and maturity during forced aeration composting of chicken manure and sawdust at different $\mathrm{C} / \mathrm{N}$ ratios. Chemosphere 78:614-619

Golueke CG (1981) Principles of biological resources recovery. Biocycle 22:36-40

Guo R, Li G, Jiang T, Schuchardt F, Chen T, Zhao Y, Shen Y (2012) Effect of aeration rate, $\mathrm{C} / \mathrm{N}$ ratio and moisture content on the stability and maturity of compost. Bioresour Technol 112:171-178

Hay JXW, Wu TY, Teh CY, Jahim JM (2012) Optimized growth of Rhodobacter sphaeroides O.U.001 using response surface methodology (RSM). J Sci Ind Res 71:149-154

Iqbal MK, Shafiq T, Ahmed K (2010a) Effect of different techniques of composting on stability and maturity of municipal solid waste compost. Environ Technol 31:205-214 
Iqbal MK, Shafiq T, Hussain A, Ahmed K (2010b) Effect of enrichment on chemical properties of MSW compost. Bioresour Technol 101(15):5969-5977

Jadhav SB, Surwase SN, Phugare SS, Jadhav JP (2013) Response surface methodology mediated optimization of Remazol Orange decolorization in plain distilled water by Pseudomonas aeruginosa BCH. Int J Environ Technol 10:181-190

Kulcu R, Yaldiz O (2004) Determination of aeration rate and kinetics of composting some agricultural wastes. Bioresour Technol 93(1):49-57

Kumar M, Ou YL, Lin JG (2010) Co-composting of green waste and food waste at low C/N ratio. Waste Manag 30(4):602-609

Mannan S, Fakhrul-Razi A, Alam MZ (2007) Optimization of process parameters for the bioconversion of activated sludge by Penicillium corylophilum using response surface methodology. J Environ Sci 19(1):23-28

Said-Pullicino D, Erriquens FG, Gigliotti G (2007) Changes in the chemical characteristics of water-extractable organic matter during composting and their influence on compost stability and maturity. Bioresour Technol 98(9):1822-1831

Senesi N (1989) Composted materials as organic fertilizers. Sci Total Environ 81:543-550
Sundberg C, Yu D, Whittle IF, Kauppi S, Smars S, Insam H, Romantschuk M, Jonsson H (2013) Effects of pH and microbial composition on odour in food waste composting. Waste Manag 33(1):204-211

Tejada M, Garcia-Martinez AM, Parrado J (2009) Relationships between biological and chemical parameters on the composting of a municipal solid waste. Bioresour Technol 100:4062-4065

Usharani K, Muthukumar M (2013) Optimization of aqueous methylparathion biodegradation by Fusarium sp in batch scale process using response surface methodology. Int $\mathbf{J}$ Environ Sci Technol 10:591-606

Wang YX, Lu ZX (2005) Optimization of processing parameters for the mycelia growth and extracellular polysaccharide production by Boletus spp. ACCC 50328. Process Biochem 40:1043-1051

Wong JWC, Fang M (2000) Effect of lime addition on sewage sludge composting process. Water Res 34(15):3691-3698

Wong JWC, Fung SO, Selvam A (2009) Coal fly ash and lime addition enhances the rate and efficiency of decomposition of food waste during composting. Bioresour Technol 100:3324-3331 